\title{
Conhecimento etnobotânico dos Tremembé da Barra do Mundaú sobre as frutas da sociobiodiversidade
}

\author{
Ethnobotanical knowledge of the Tremembé of Barra of Mundaú on the \\ sociobiodiversity fruits
}

\section{Connaissances ethnobotaniques du Tremembé du Barra de Mundaú sur les fruits de la sociobiodiversite}

\section{Conocimiento etnobotánico de los Tremembé de la Barra del Mundaú sobre las frutas de la sociobiodiversidad}

\author{
André Luís Aires Pinto ${ }^{1}$ \\ Francisca Joseli Freitas de Sousa ${ }^{1}$ \\ Maria do Socorro Moura Rufino ${ }^{1}$ \\ Recebido em 20/06/2017; revisado e aprovado em 17/10/2017; aceito em 01/11/2017 \\ DOI: http://dx.doi.org/10.20435/inter.v19i4.1632
}

\begin{abstract}
Resumo: A pesquisa objetivou identificar as frutas nativas do território dos Tremembé da Barra do Mundaú e seu valor cultural. Adotou-se a etnografia, envolvendo diário de campo, entrevistas e observação participante. As principais formas de uso foram alimentares, artesanais, medicinais e ritualísticas, mostrando que a relevância das frutas vai além do aspecto nutricional, estando associada ao conhecimento tradicional com várias de suas práticas culturais e identitárias.
\end{abstract}

Palavras-chaves: frutas; etnobotânica; formas de uso.

Abstract: The research aimed to identify the native fruits of the territory of the Tremembé of Barra do Mundaú and its cultural value. Ethnography was adopted, involving field diary, interviews and participant observation. The main forms of use were food, handicrafts, medicinal and ritualistic, showing that the relevance of fruits goes beyond the nutritional aspect, being associated with traditional knowledge with several of their cultural and identity practices.

Keywords: fruits; ethnobotany; forms of use.

Résumé: La recherche visait à identifier les fruits indigènes du territoire des Tremembé de Barra do Mundaú et sa valeur culturelle. L'ethnographie a été adoptée, avec un journal de terrain, des interviews et des observations de participants. Les principales formes d'utilisation étaient la nourriture, l'artisanat, médicinal et rituel, montrant que la pertinence des fruits va au-delà de l'aspect nutritionnel, étant associée aux connaissances traditionnelles avec plusieurs de leurs pratiques culturelles et identitaires.

Mots-clés: fruits; ethnobotanique; formes d'utilisation.

Resumen: La investigación objetivó identificar las frutas nativas del territorio de los Tremembé de la Barra do Mundaú y su valor cultural. Se adoptó la etnografía, envolviendo diario de campo, entrevistas y observación participante. Las principales formas de uso fueron alimenticias, artesanales, medicinales y rituales, mostrando que la relevancia de las frutas va más allá del aspecto nutricional, estando asociada al conocimiento tradicional con varias de sus prácticas culturales e identitarias.

Palabras claves: frutas; etnobotánica; formas de uso.

\section{INTRODUÇÃO}

A pesquisa sobre o conhecimento etnobotânico dos Tremembé2 da Barra do Mundaú acerca das frutas da sociobiodiversidade possibilitou observar que o grupo pesquisado detém um vasto

\footnotetext{
${ }^{1}$ Universidade da Integração Internacional da Lusofonia Afro-Brasileira (UNILAB), Redenção, Ceará, Brasil.

${ }^{2}$ Os Tremembé da Barra do Mundaú são um povo indígena que habita o litoral oeste do Estado do Ceará.
} 
conhecimento botânico das espécies nativas de suas terras, com alguns usos e nomenclaturas muito particulares. O "conhecimento tradicional", também denominado "etnociência" (SANTOS; MENESES; NUNES, 2005), diz respeito a conjuntos de conhecimentos construídos e reconstruídos historicamente no seio de dada população tradicional; nas últimas décadas, os termos queriam chamar a atenção para a diversidade de sistemas de conhecimento existentes. O conhecimento tradicional é um ponto presente na discussão acerca da reprodução cultural de grupos étnicos. Esse patrimônio imaterial, expresso nos conhecimentos, distingue os grupos e faz parte de sua identidade cultural.

A relação dos Tremembé com o território e sua biodiversidade criam as bases para a construção de um conhecimento intimamente ligado com a identidade desse povo, que depende da terra para sua sobrevivência e constituição identitária. O território é definido como uma porção da natureza e espaço sobre o qual uma sociedade determinada garante a seus membros, através de reivindicações políticas, direitos estáveis de acesso, controle ou uso sobre os recursos naturais aí existentes, necessários à sua sobrevivência (GODELIER, 1984 apud DIEGUES, 1999, p. 19). Visão compartilhada por Santilli (2005, p. 94), que entende o conceito de território, como "o espaço necessário à reprodução física e cultural de cada grupo, considerando suas formas de uso diferenciadas". Oliveira (1999, p. 24) denomina de processo de territorialização o movimento pelo qual um objeto político-administrativo, que é a terra, se torna o ponto central da organização coletiva de um grupo que passa a se organizar, formular uma identidade própria, instituir mecanismos de tomadas de decisão e representação e estruturar formas de reprodução cultural, incluindo múltiplas formas de relação com o meio ambiente e com o universo religioso.

No intuito de refletir sobre os conhecimentos botânicos dos Tremembé sobre as frutas da sociobiodiversidade, adotamos o conceito de etnobotânica como sendo o estudo das interrelações materiais e simbólicas entre o ser humano e as plantas, somando-se os fatores ambientais e culturais, bem como os conceitos locais que são desenvolvidos acerca das plantas e os usos que se fazem delas (COELHO; COSTA JUNIOR; DOMBROSKI, 2003). Aplica-se ainda o conceito de sociobiodiversidade àqueles recursos da biodiversidade relativos ao território, ao conhecimento tradicional, às práticas culturais, rituais, aos hábitos alimentares, às relações econômicas e de produção de um determinado povo ou comunidade tradicional.

Em consonância ao discurso das frutas como recurso alimentar, os especialistas indígenas colocaram suas impressões sobre a conservação. Sua relação com a terra lhes permite perceber a erosão genética sofrida por algumas espécies, a escassez de outras, e a oscilação de produtividade, atestando a falta ou ainda a abundância em determinadas safras. A dependência e a estreita relação com os recursos naturais faz com que essas pessoas conheçam os ciclos da natureza e os recursos disponíveis. Um estudo da Organização das Nações Unidas para a Alimentação e a Agricultura (FAO) estima que, no último século, se perderam em torno de três quartos da diversidade genética das variedades agrícolas cultivadas (FAO, 2008). Esses recursos genéticos são a base biológica da segurança alimentar mundial e, direta ou indiretamente, sustentam quase todos os meios de vida humana do planeta.

Os Tremembé demonstram sofisticado conhecimento ecológico, transmitido de geração a geração. São conhecimentos etnobotânicos e etnobiológicos desenvolvidos a partir da cosmologia tremembé, da convivência dos antigos com o meio ambiente, com a terra e suas formas de vida. Os Tremembé conhecem profundamente bioindicadores, etologia de algumas espécies e sua relação com a alternância das fases do ciclo hidrológico e com a biogeografia 
dos corpos d'água do seu território. Por sua vez, eles apresentam um sistema detalhado de classificação de ambientes terrestres e aquáticos, o que demonstra o conhecimento acumulado ao longo da ocupação duradoura e tradicional na área a que posteriormente foi delimitada (FRANCO, 2012).

Portanto a pesquisa buscou identificar as frutas do território dos Tremembé da Barra do Mundaú com os seus principais usos, os conhecimentos associados e a categorização daquelas consideradas pelos especialistas indígenas mais relevantes para sua cultura.

\section{METODOLOGIA}

O trabalho busca uma reflexão antropológica acerca do conhecimento etnobotânico dos Tremembé da Barra do Mundaú sobre as frutas da sociobiodiversidade, ele faz referência a conhecimentos produzidos por outras áreas, especialmente pela botânica. Estudos antropológicos foram fundamentais à compreensão de conceitos como os de etnicidade e conhecimento tradicional, e os estudos biológicos forneceram valiosos subsídios para entender a etnobotânica, perceber a biodiversidade de espécies e ecossistemas presentes na Terra Indígena e a relevância para a cultura daquele povo.

A pesquisa adotou a metodologia com abordagem qualitativa, de cunho etnográfico, apresentando a identificação das frutas utilizadas pelos indígenas. No estudo das espécies frutíferas, foram abordados seus usos medicinais, alimentares, ritualísticos e artesanais. Para Ingold (2012), a etnografia é uma tarefa de descrição da vida das pessoas com o máximo possível de precisão e verdade, sem tratá-la como apenas uma coleta de dados, sendo danoso tratá-la apenas como um método, uma vez que poderia ser considerada uma vocação ou modo de vida.

A etnografia foi realizada entre 2015 e 2016, com visitas mensais ao território tremembé, como recomenda Geertz (1989); dentre outros procedimentos, consistiu em estabelecer relações, manter diário de campo, realizar registros fotográficos, transcrições das entrevistas e coleta de amostras botânicas.

Dentre as frutas estudadas, dezoito amostras das espécies vegetais férteis foram depositadas no Herbário Prisco Bezerra, da Universidade Federal do Ceará. Realizou-se a coleta das amostras em campo, segundo orientação da Profa. Iracema Bezerra e o apoio de sua equipe, estas sendo usadas para a montagem das exsicatas, com local de coleta georreferenciado e seus respectivos números de registro fornecidos pelo herbário.

\section{RESULTADOS E DISCUSSÕES}

De acordo com Josué de Castro (2010, p. 184), sem o cultivo de plantas frutíferas, resta ao sertanejo o recurso bem limitado das frutas silvestres - do umbu, do pequi, do quibá, da cajarana e da quixaba. O consumo de verduras é também limitado à abóbora (Curcubita maxima), ao maxixe (Cucumis anguria) e às cebolinhas (Allium fistulosum) e coentros (Coriandrum sativum) usados como tempero. O consumo das "frutas do mato" pode ser entendido como uma herança de povos nômades ou seminômades, que aproveitavam, de forma extrativista, o que a natureza Ihes oferecia gratuitamente. Josué de Castro (2010, p. 194-5) reflete ainda que existem, no sertão, fontes ignoradas de apreciável riqueza em ácido ascórbico, além do leite: os frutos silvestres, como o umbu, o cajuí e outros ainda mais desprezados, como o juá e o quibá, os quais têm se mostrado extraordinariamente ricos nessa vitamina. 
Uma relevante demonstração da importância das frutas para os Tremembé está no uso ritualístico. A realização da "festa do murici e do batiputá" foi incorporada à cultura dos Tremembé e se constitui como um importante espaço onde os traços diacríticos (BARTH, 2000) daquele povo são evidenciados para eles e para a comunidade envolvente. As duas frutas, consideradas sagradas, são festejadas no período coincidente de suas safras. Durante uma semana, o povo indígena organiza uma série de atividades, mantém os corpos permanentemente pintados com jenipapo e dança o torém diariamente. O torém é uma dança sagrada para os Tremembé e, durante sua execução, bebe-se o mocororó, bebida à base de caju. Há algumas cantigas de torém, cujas letras fazem referência às frutas, o que denota sua importância para a formação identitária do grupo.

Na nossa terra tem murici, batiputá Um serve de alimento, outro serve pra curar. Nós vamos fazer o óleo do nosso batiputá O pessoal que vem de fora, todo mundo quer olhar.

Quanto ao uso alimentar, pode se dizer que as frutas comestíveis da sociobiodiversidade têm enriquecido a dieta de várias populações, graças ao seu alto conteúdo em substâncias bioativas, do que se pode afirmar que seu consumo, assim como de outros vegetais silvestres comestíveis, tem influência positiva na saúde de seus consumidores (TARDÍO, 2011). Albuquerque (2014) chama a atenção para as propriedades nutricionais de plantas alimentícias não convencionais, dentre elas o coco-babão (Syagrus cearenses), o juazeiro (Ziziphus joazeiro) e a goiaba (Psidium schenckianum). O autor aponta a necessidade de se buscar estratégias de sensibilizar os jovens ao consumo dessas frutas, uma vez que, influenciados pela modernização, eles têm demonstrado desinteresse no conhecimento e uso dessas espécies.

A tabela 1 mostra as frutas existentes na Terra Indígena Tremembé da Barra do Mundaú em Itapipoca, Ceará, que foram relatadas pelos colaboradores indígenas da pesquisa. Sua identificação botânica inclui nomes populares, científicos e famílias de todas as plantas referidas nas entrevistas, realizadas na comunidade com seus respectivos usos.

Tabela 1- Espécies frutíferas encontradas na Barra do Mundaú e seus respectivos usos

\begin{tabular}{llll}
\hline Nome popular & Família & Gênero/espécie & Usos \\
\hline Ameixa & Olacaceae & Ximenia americana L. & AL., ME., AA., AR \\
Angélica & Rubiaceae & Guettarda angelica Mart. ex Müll. Arg. & AL., ME., AA. \\
Araticum & Annonaceae & Annona coriacea Mart. & AL., AA., AR. \\
Azeitona & Myrtaceae & Syzygium cumini (L.) Skeels & AL., AA. \\
Batiputá & Ochnaceae & Ouratea fieldingiana Engl & ME., AL., AA. \\
Caju & Anacardiaceae & Anacardium occidentale L. & AL., ME., RI, AA. \\
Canapum & Solanaceae & Physalys augulata L. & AL., ME., AA. \\
Canela de veado & Rutaceae & Helietta apiculata Benth. & ME; AA. \\
Mandacaru & Cactaceae & Cereus jamacaru DC. & AL; AA; AR. \\
Carnaúba & Arecaceae & Copernicia prunifera (Mill.) H.E. Moore & AL; AA; AR. \\
Chichá & Malvaceae & Sterculia apetala (Jacq.) H. Karst. & AL; AR. \\
Croatá & Bromeliaceae & Neoglaziovia variegata (Arruda) Mez & AL; ME; AR. AA. \\
Geniparana & Lecythidaceae & Gustavia augusta L. & AL; AR;AA. \\
Goiaba & Myrtaceae & Psidium L. & AL; AA. \\
Goiti & Chrysobalanaceae & Licania tomentosa (Benth.) Fritsch & AL; AA.
\end{tabular}




\begin{tabular}{llll}
\hline Nome popular & Família & Gênero/espécie & Usos \\
\hline Guabiraba & Myrtaceae & Campomanesia viatoris Landrum & AL; Rl; AA. \\
Guajiru & Chrysobalanaceae & Chrysobalanus icaco L. & AL; ME; AA. \\
Gulari & Loganiaceae & Strychnos parvifolia A.DC. & AL; AA. \\
Grão de galo & Celastraceae & Maytenus erythroxyla Reissek & AL; AA. \\
Jaracatiá & Caricaceae & Jacaratia spinosa15 (Aubl) A.DC. & AL; AA. \\
Jatobá & Fabaceae & Hymenaea courbaril L. var. courbaril & AL; ME; AR. \\
Jatobá negro & Fabaceae-Caes & Hymenaea courbaril L. & AL; ME; AR. \\
Jenipapo & Rubiaceae & Genipa americana L. & AL; AR;AA. \\
Juazeiro & Rhamnaceae & Zizyphus joazeiro16 Mart. & AL; AA; RI. \\
Maracá chumbim & Verbenaceae & Lantana camara L. & AL;AA; ME. \\
Maracujazinho & Passifloraceae & Passiflora sub-rotunda Mast. & AL; AA. \\
Melancia-da-praia & Solanaceae & Solanum capsicoides All. & AL; AA. \\
Melão caetano & Cucurbitaceae & Momordica charantia L. & AL; ME; AA. \\
Monguba & Bombacaceae & Pachira aquática Aubl. & AL; \\
Murici & Malpighiaceae & Byrsonimia crassifolia L. (Kunt.) & AL;AA. \\
Murici pitanga & Malpighiaceae & Byrsonimia aff. crassifolia L. (Kunt.) & AL;AA. \\
Mutamba & Malvaceae & Guazuma ulmifolia Lam. & AL; AA. \\
Oiticica & Chrysobalanaceae & Licania rigida Benth. & AL;AA. \\
Panã & Anonaceae & Annona cearenses Huber. & AL;AA. \\
Pitomba & Sapindaceae & Talisia esculenta (Cambess.) Radlk. & AL. \\
Puçá & Melastomataceae & Mouriri cearensis Huber & AL;AA. \\
\hline
\end{tabular}

Legendas: AL: alimentar; ME: medicinal; RI: ritualístico; AA: alimentação animal; AR: artesanato.

Fonte: Elaborado pelos autores.

A pesquisa de campo registrou mais de trinta espécies de frutas nativas, "frutas do mato", frutas silvestres ou da sociobiodiversidade, de ocorrência na Terra Indígena Tremembé da Barra do Mundaú. Dentre elas, destacam-se o murici (Byrsonimia crassifolia) e o murici pitanga (Byrsonimia aff. crassifolia), o batiputá (Ouratea fieldingiana), o caju (Anacardium occidentale), o guajiru (Chrysobalanus icaco), o jatobá (Hymenaea courbaril), o jatobá negro (Hymenaea) e a ubaia amarela (Eugenia dysenterica). Rufino (2004) classificou o habitat dessas frutas como vegetação subperenifólia das dunas estabilizadas, destacando a importância desses recursos vegetais para as populações locais, direcionando atenção para a necessidade do estudo de novas frutas, tanto para fins comerciais como de preservação, tendo em vista que a ocupação da região litorânea vem causando a erosão genética dessas espécies.

\section{Murici (Byrsonimia crassifolia L. Kunt.)}

A palavra "murici" provém do Tupi mboricí, ou seja, faz resinar (BRAGA, 1976). Os muricis do Brasil são muitos e variados, sendo, em sua maioria, plantas da família Malpighiaceae. Em suas diferentes espécies, os muricis distinguem-se, também, por suas cores e locais de ocorrência (LOURENÇO, 2008). Assim, são conhecidos o murici-amarelo (Cassia verrucosa), da família das leguminosas-Cesalpiniáceas; o murici-da-serra (Vochysia saldanhae), da família das Voquisiaceae, e os muricis da família Malpighiaceae, tais como: o murici-pequeno (Byrsonima verbascifolia), o murici-de-flor-vermelha (B. punctulata), o murici-da-chapada (B.salzmanniana), o murici-dascapoeiras (B. lancifolia), o murici-do-campo (B.crassifolia; B.intermedia), entre outros (CORRÊA, 1974). 
Figura 1- Frutos e inflorescências de Murici
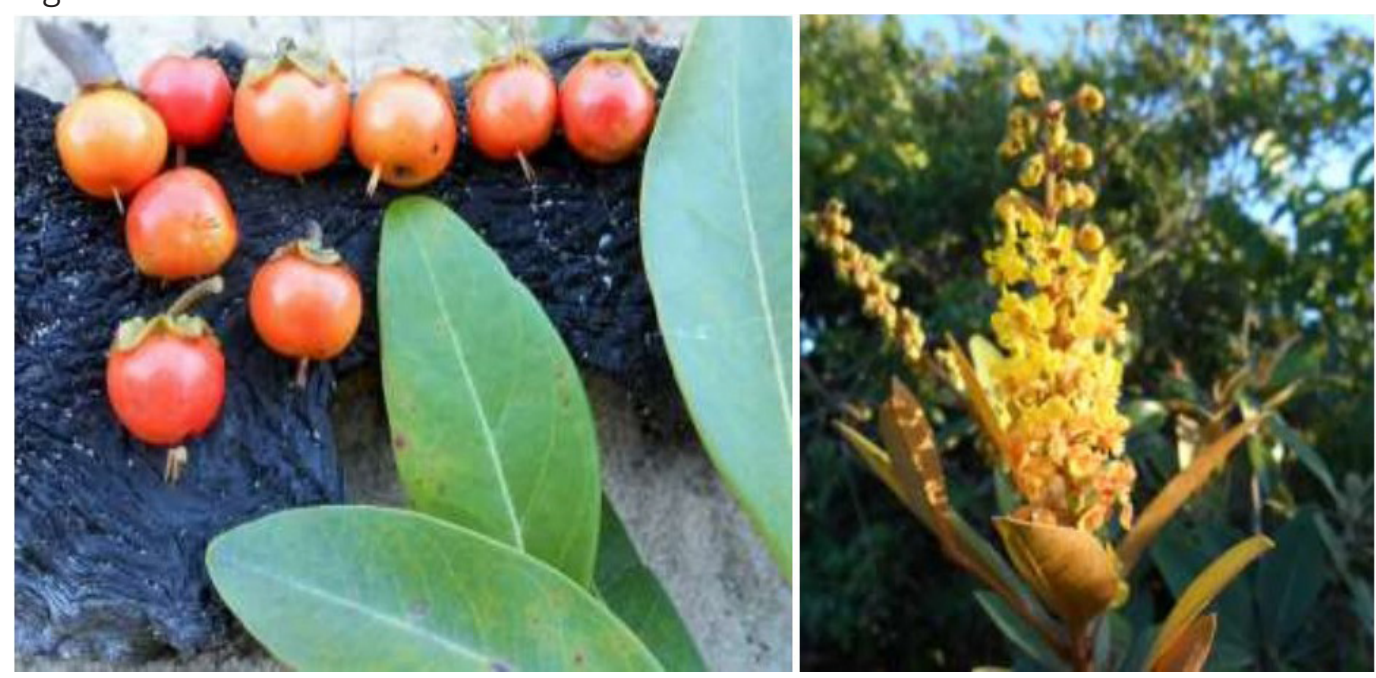

Foto: André Pinto

O murici, em sua safra, é fonte de trabalho para muitas famílias litorâneas que têm, no extrativismo da fruta, uma oportunidade de renda e de fonte de nutrientes. O fruto é coletado principalmente por mulheres e crianças, aproveitando a mão de obra disponível. Além da sua relevância para as comunidades, está sua importância para a fauna local. Quanto a isso, pouco se conhece sobre a sua reprodução, requerimentos de polinização, agentes polinizadores, sucesso reprodutivo da espécie e outros aspectos importantes para assegurar a sua perpetuação (PEREIRA, 2001). A necessidade de estudos sobre qualidade pós-colheita de frutos de muricizeiro se faz óbvia, objetivando complementar pesquisas realizadas sobre técnicas de propagação e cultivo, de modo que, uma vez implantados os pomares, os produtores estejam prontos a colocar os frutos no mercado em condições competitivas de qualidade e vida útil. Além disso, dispondo do conhecimento da qualidade e do potencial de utilização dos frutos pode-se classificá-los de acordo com sua aptidão, ou seja, industrialização e/ou consumo in natura (LOURENÇO, 2008).

\section{Batiputá (Ouratea fieldingiana Gardner Engl.)}

O batiputá é um arbusto cujo nome advém do vocabulário indígena, sendo corruptela de abatiputá, árvore de muitos frutos, equivalendo a ibá, árvore, ti, fruto, etá, muitos. A abundância das pequenas frutas negro-azuladas, em densos cachos, oportuniza o largo aproveitamento de seu óleo usado na alimentação e na indústria. As plantas crescem preferencialmente nos tabuleiros arenosos do litoral. Suas sementes moles, fáceis de esmagar, produzem óleo finíssimo aplicado como emoliente em tumores, em friç̧ões nas dores reumáticas, como cicatrizante, inclusive para queimaduras e para úlceras gástricas (BRAGA, 1976). 
Figura 2- Frutos de Batiputá

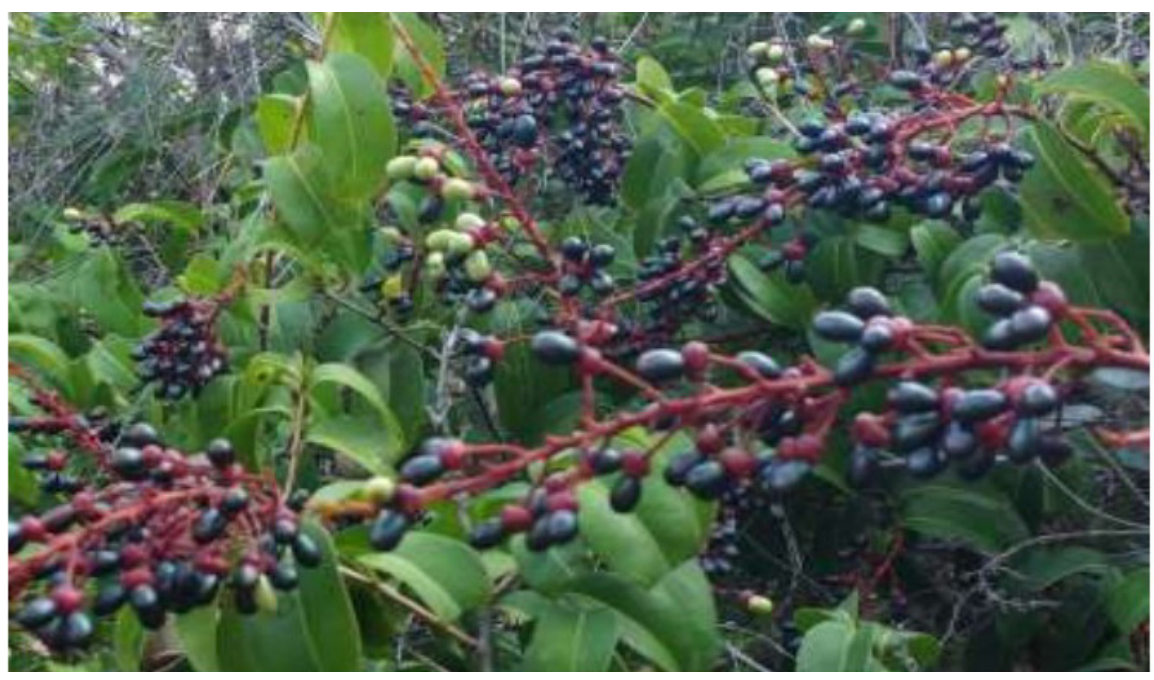

Foto: André Pinto.

Ao considerar o batiputá como planta sagrada, os Tremembé criam regras para sua exploração sustentável, a colheita da produção e proteção da espécie. Há a interdição de usar queimadas em áreas novas, onde há a presença das frutíferas, norma que tem causado conflitos com posseiros que ainda estão na área. Para os indígenas do grupo pesquisado, o óleo do batiputá é um medicamento com uma infinidade de aplicações terapêuticas, o que faz dele algo extraordinário, indissociável à identidade do grupo e aos seus costumes, como mostra a fala de um indígena:

A primeira fruta que temos aqui é uma semente conhecida por batiputá, que é um remédio muito santo. Quase todas as doenças o batiputá cura. O batiputá ele cura tumor, dor de cabeça, inflamação, dor de dente. Se a pessoa leva um golpe, a pessoa pega o óleo, amorna e bota, num instante sara. Vamos supor, se aparece assim uma coceira no corpo, pode esquentar e colocar em cima e esfregar. Se tem dor de cabeça, pode passar o óleo na fronte que cura. (Valdir, puxador de torém).

O conhecimento acerca do batiputá pode ser compreendido como um elemento diacrítico de formação da identidade tremembé. É um conhecimento que o grupo detém, desenvolvido em sua tradicional relação com a natureza e que os distingue da sociedade envolvente, tanto que é reconhecido e valorizado por não índios.

\section{Jenipapo (Genipa americana L.)}

A etimologia de jenipapo, em tupi-guarani, "fruta que serve para pintar", remete à propriedade corante da substância extraída desse fruto. A árvore do jenipapo tem um porte elegante, com até $10 \mathrm{~m}$ de altura, bem ramificada e bastante frondosa. Suas folhas são opostas, simples, glabras, de 15-35 cm de comprimento. Seu fruto tem polpa vinosa escura e adocicada com numerosas sementes compridas, achatadas e de cor acinzentada. Sua madeira, moderadamente pesada, flexível e compacta, é fácil de trabalhar, sendo empregada em móveis de luxo, construção naval, obras de torno, construção civil etc. (BRAGA, 1976; LORENZI, 2008).

Pesquisas mostram a eficácia do corante azul, cujo pigmento é o geniposídeo, para a indústria alimentícia. Esse pigmento pode ser extraído do jenipapo ainda verde, a partir da diluição em água ou álcool, assim como é feito pelos indígenas para a fabricação de tintura para 
a pele. Seu uso pode ser muito benéfico à indústria alimentícia, tendo em vista que os corantes alimentícios azuis são artificiais e prejudiciais à saúde; o fruto maduro, doce e comestível pode ser consumido in natura, na forma de suco, doces, licores. Já do fruto verde, rico em tanino, extrai-se um suco tintorial de cor escura (RENHE, 2009).

Figura 3 - Frutos de Jenipapo

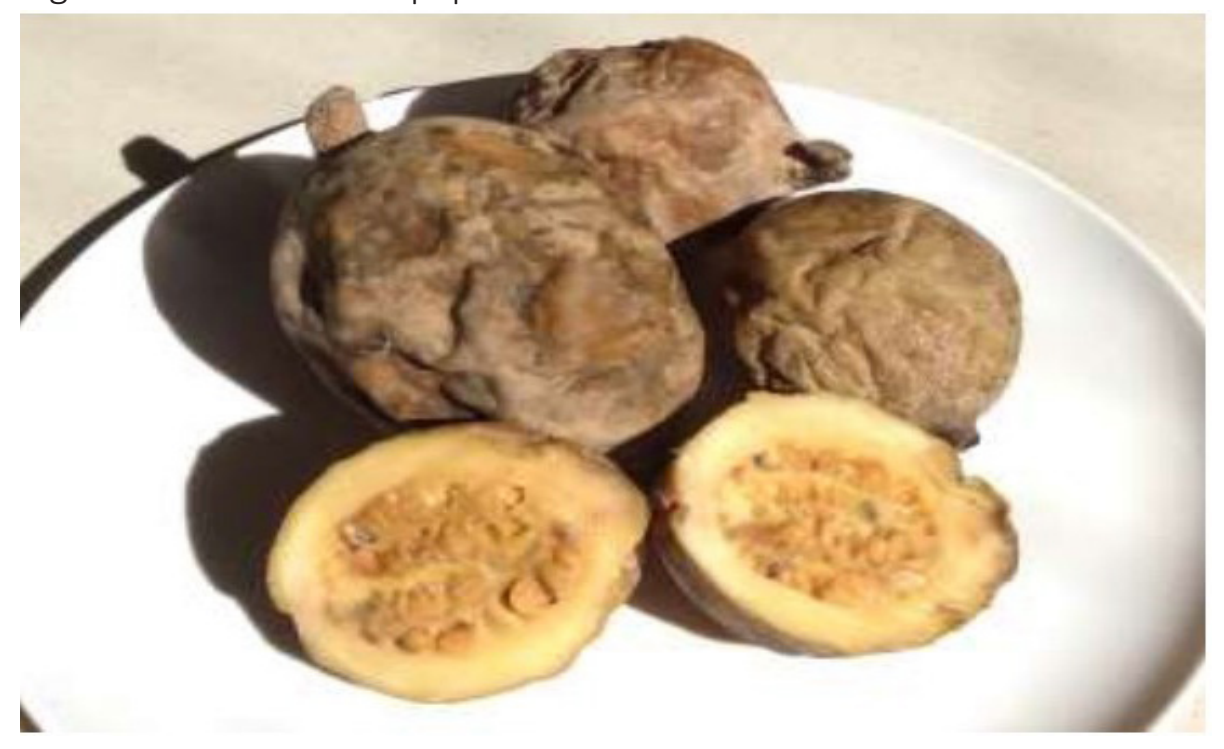

Foto: André Pinto.

Entre os Tremembé, as pinturas corporais falam de sua cosmologia. Algumas fazem em referência ao mar, aos peixes, aos movimentos das ondas e das marés. As formas geométricas, cuidadosamente traçadas no corpo, demarcam a sua relação com o território e os recursos naturais. São sinais diacríticos que identificam os indígenas para fora do grupo, delimitando fronteiras étnicas (BARTH, 2000). No âmbito interno ao grupo, as pinturas são estimuladas desde cedo, como forma de exaltação e valorização cultural dos Tremembé. As partes mais pintadas são braços e pernas, por serem mais facilmente expostas e visualizadas.

\section{Carnaúba (Copernicia cerifera Mart.)}

A palavra "carnaúba" advém do tupi (carana, iwa), de carnaíba (FERREIRA, 1986) ou carnaúba, sendo caraná, palmeira que arranha, escamosa, cascuda e iba ou uba, árvore (BRAGA, 1976). O autor descreve densamente a carnaúba (Copernicia cerifera Mart.) como uma bela palmeira de espique único e reto, podendo chegar a 20 metros de altura, dividida em três partes. A primeira, no terço inferior da árvore, conserva aderentes as bases de seus pecíolos espinhosos, de formato semitriangular, avermelhado, que lhe confere proteção inclusive contra incêndios. A segunda, que é a maior porção, quase cilíndrica, apresenta-se nua (carnaúba lisa ou carnaúba lavada) e guarda, dos vestígios foliáceos apenas ligeiras cicatrizes, tendo coloração brancacenta ou acinzentada, raramente avermelhada ou escura. A última é o gomo terminal (olho), acompanhado da copa, de onde brotam os frutos e de cujas folhas se extrai a cera, importante produto de exportação.

A fruta tem importância alimentar e medicinal para os Tremembé, como exposto na narrativa abaixo de uma liderança indígena: 
A fruta da carnaúba dá um cachão que fica pendurado. A fruta é verde, mas quando fica madura ela é preta. Na fome demais, a gente comia. Raspava com os dentes, comendo a casca por riba. Aí você pega com uma faca e raspa a fruta até ficar só o caroço, aí quando chegava no caroço a gente batia, batia com um pau, até quebrar pra tirar o miolinho de dentro. Aquele caroço ali, pra tirar um bocado dá muito trabalho. Aí, aqueles carocinhos a gente cortava com um facão ou uma faca, bem pequenininho, do tamanho de um grão de café, ai pegava, escaldava pra tirar o amarujo, coava, botava num jirau, no sol, em riba de uma tábua, que era pra quando ele tivesse sequinho, bem sequinho, misturar com aquele café que ela mandava comprar, né? Aí pegava o café e torrava, torrava, torrava. Quando estava bem torradinho é que botava o outro pra misturar. Os homens tudo eram sadios. As mulheres tudo eram sadias, quem tomasse o café do caroço da carnaúba. Aí serve pra aquelas pessoas que têm pouco sangue, doente de anemia. O caroço, sendo só ele mesmo, torrado no caco, você pode tomar pra anemia e é fácil, assim a pessoa tenha coragem de fazer. (Francisco Rosa Veríssimo, 81 anos).

Figura 4- Frutos de Carnaúba

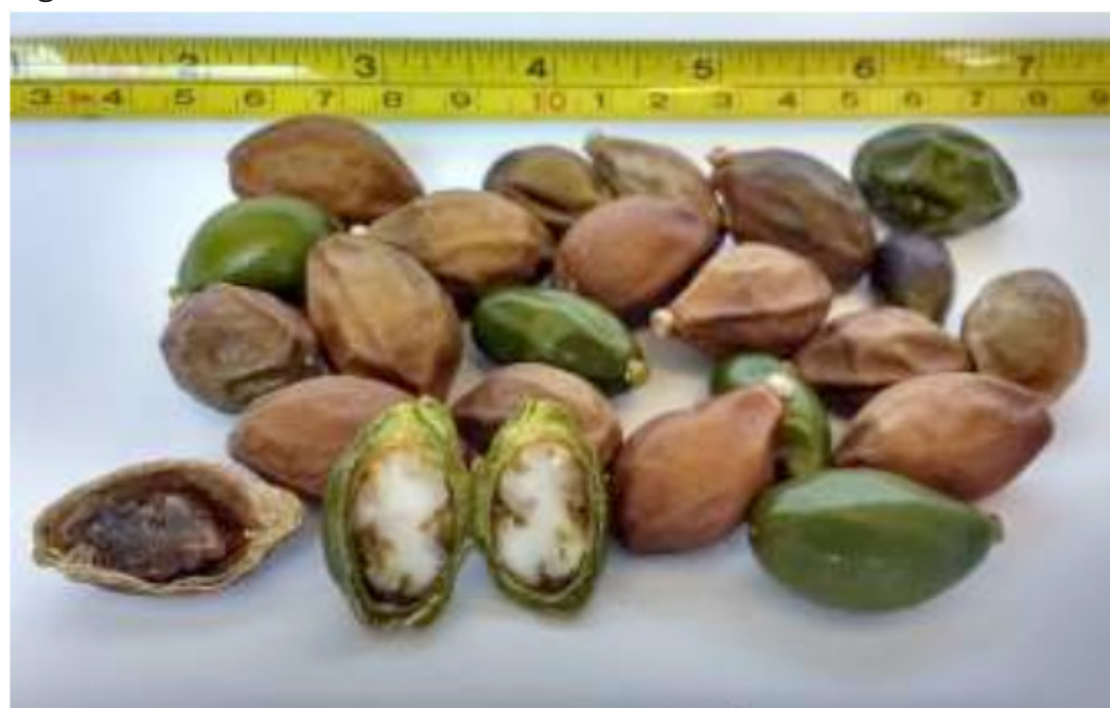

Foto: André Pinto.

\section{Ubaia amarela (22Mart. DC.)}

A ubaia amarela (Eugenia dysenterica), da família das Mirtáceas, é um arbusto de floração branca, baga pequena, piriforme, de casca amarela avermelhada ou alaranjada com uma a duas sementes grandes, coberta com polpa aquosa doce e um tanto ácida. Com ocorrência nos tabuleiros da região litorânea de quase todo o Brasil conhecida também por uvalha ou uvaia (BRAGA, 1976), que, segundo o Dicionário Aurélio, deriva do tupi iwa'ya fruto ácido, azedo. 
Figura 5- Frutos de Ubaia amarela

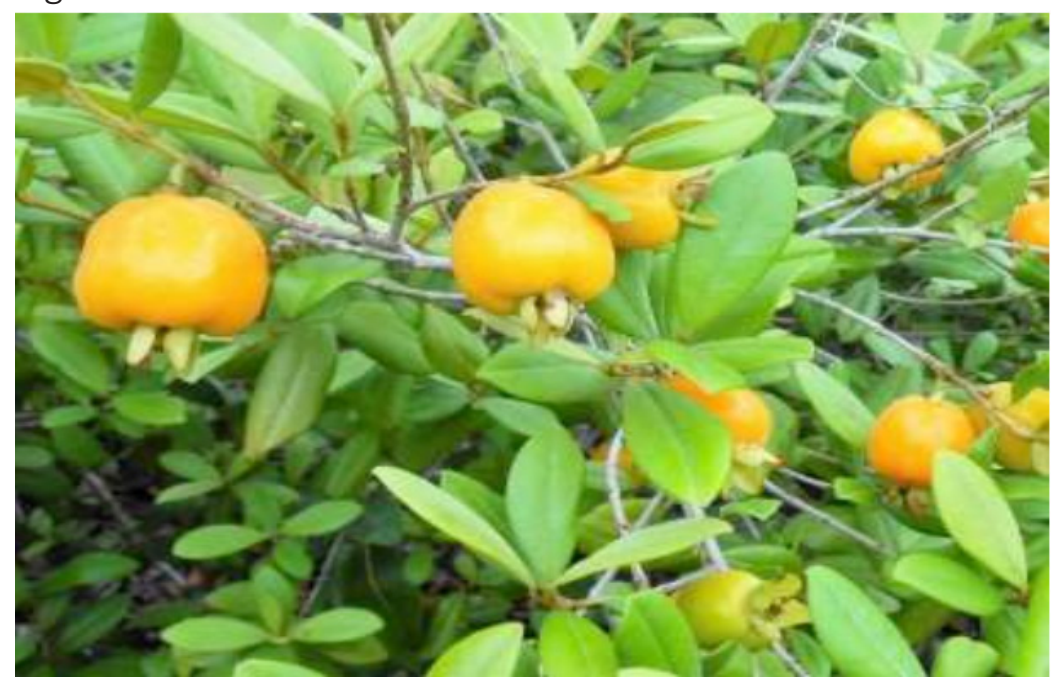

Foto: André Pinto.

Entre os Tremembé, a fruta é muito apreciada, sendo consumida in natura ou em sucos. É fácil encontrar pés de ubaia na Terra Indígena. Na época de sua floração, as plantas ficam quase sem folhas com os galhos tomados por flores brancas, de agradável odor, um atrativo para abelhas, que abundantemente rondam as plantas, principalmente nas primeiras horas do dia. Um passeio pela mata durante os meses de safra, traz a recompensa do fruto refrescante, colhido no pé.

Muitas das plantas nativas são utilizadas por populações locais de baixa renda como medicinais, alimentos e geração de renda, através de sua coleta e venda. Pouco ainda se sabe sobre os reais potenciais dessas frutas, já que ficaram esquecidas e subutilizadas durante muito tempo. Graças a esforços mundiais e à conscientização das populações, estas vêm ganhando espaço no meio científico, visando ao conhecimento de seus potenciais em várias áreas de utilização. O desenvolvimento de pesquisas que visem garantir a preservação e a diversidade genética do germoplasma ${ }^{3}$ dessas espécies, bem como as que resultem na geração de conhecimento e tecnologia que venha permitir o cultivo racional e econômico, além de melhores formas de aproveitamento, são importantes no sentido de melhorar as oportunidades de emprego e renda, especialmente no meio rural, tendo em vista o desenvolvimento sustentável da região (LOURENÇO, 2008, p. 1-2).

\section{CONSIDERAÇÕES FINAIS}

Para que haja desenvolvimento sustentável, é necessária a adoção de um conjunto de medidas que valorizem os produtos da sociobiodiversidade, criando cadeias produtivas rentáveis para as populações locais, de modo a valorizar a biodiversidade conservada, criar incentivos a iniciativas populares e cooperativistas e promover apoio técnico, acesso a informação e a tecnologias. Aponta-se a necessidade de se buscar estratégias de sensibilizar os jovens ao consumo dessas frutas, uma vez que, influenciados pela modernização, eles têm demonstrado desinteresse no conhecimento e uso dessas espécies.

\footnotetext{
${ }^{3}$ Qualquer material genético que possa dar origem a novos indivíduos, como sementes ou a planta em si.
} 
A maioria das frutas citadas na pesquisa são aproveitadas como alimento in natura. Não obstante o consumo da fruta em si, outras partes das plantas frutíferas apresentam aplicações variadas. Atualmente, essas frutas ainda são consideradas por alguns como "comida de pobre", a despeito de seu significativo potencial alimentar e nutricional. A diversidade de frutas disponíveis, diferentes das frutas convencionais, oferece uma rica fonte de nutrientes, para além, vários autores ressaltam o potencial alimentar das frutas nativas ou não convencionais, seja na forma in natura, beneficiada ou industrializada.

Faz-se necessário o aprofundamento de pesquisas sobre o conhecimento tradicional acerca das frutas nativas. Seu uso alimentar, medicinal, ou mesmo ritualístico, e seu potencial econômico para as comunidades da região objeto de estudo podem se caracterizar como formas de resistência frente à erosão genética e à degradação dos recursos naturais, contribuindo para a valorização da cultura regional e uma melhoria da condição nutricional da população.

\section{Agradecimentos}

À CAPES pelo apoio financeiro e ao Grupo de Pesquisa POLIFIBAN/CNPq.

\section{REFERÊNCIAS}

ALBUQUERQUE, U. P. Introdução à etnobiologia. Recife: NUPEEA, 2014.

BARTH, F. Os grupos étnicos e suas fronteiras. In: BARTH, F. O guru, o iniciador e outras variações antropológicas. Rio de Janeiro: Contra Capa, 2000. p. 25-68.

BRAGA, R. Plantas do Nordeste, especialmente do Ceará. 4. ed. Natal: UFRN, 1976.

CASTRO, J. Geografia da fome. 10. ed. Rio de Janeiro: Civilização Brasileira, 2010.

COELHO, M. F. B.; COSTA JUNIOR, P.; DOMBROSKI, J. L. D. Diversos olhares em etnobiologia, etnoecologia e plantas medicinais. In: SEMINÁRIO MATO-GROSSENSE DE ETNOBIOLOGIA E ETNOECOLOGIA, 1.; SEMINÁRIO CENTRO-OESTE DE PLANTAS MEDICINAIS, 2. Anais [...] Cuiabá: Unicen, 2003.

CORRÊA, M. P. Dicionário das plantas úteis do Brasil. Rio de Janeiro: Instituto Brasileiro de Desenvolvimento Florestal, 1974. v. 5, p. 264-9.

DIEGUES, A. C. (Org.). Os saberes tradicionais e a biodiversidade no Brasil. São Paulo: Ministério do Meio Ambiente/COBIO/NUPAB, 1999.

FERREIRA, A. B. H. Novo Dicionário Aurélio da Língua Portuguesa. 2. ed. Rio de Janeiro: Nova Fronteira, 1986. FRANCO, C. T. S. Resumo do Relatório Circunstanciado de Identificação e Delimitação da Terra Indígena Tremembé da Barra do Mundaú. Diário Oficial da União, n. 26, seção 1, p. 22-23. Brasília, segunda-feira, 6 de fevereiro de 2012.

GEERTZ, C. A interpretação das culturas. São Paulo: LCT, 1989.

INGOLD, T. Diálogos vagueiros: vida, movimento e Antropologia. Entrevista concedida a Ana Letícia Fiori et al. Ponto Urbe. Revista do Núcleo de Antropologia Urbana da USP, São Paulo, n. 11, 2012.

LORENZI, H. Árvores brasileiras: manual de identificação e cultivo de plantas arbóreas nativas do Brasil. 5. ed. Nova Odessa, SP: Instituto Plantarum, 2008. v. 1. 
LOURENÇO, I. P. Potencial de utilização de frutos de genótipos de muricizeiros cultivados no litoral do Ceará. 2008. 83f. Dissertação (Mestrado em Agronomia) - Universidade Federal do Ceará (UFC), Fortaleza, 2008.

OLIVEIRA, J. P. Uma etnologia dos "índios misturados"? Situação colonial, territorialização e fluxos culturais. In: OLIVEIRA, J. P. (Org.). A viagem da volta: etnicidade, política e reelaboração cultural no Nordeste indígena. Rio de Janeiro: Contra Capa, 1999. p. 11-39.

ORGANIZAÇÃO DAS NAÇÕES UNIDAS PARA A ALIMENTAÇÃO E A AGRICULTURA (FAO). La biodiversidad: un freno a la inseguridad alimentaria mundial. Conferência mundial sobre la diversidad biológica en Bonn. 2008. Disponível em: http://www.fao.org/Newsroom/es/news/2008/1000841/index.html. Acesso em: 20 jun. 2016.

PEREIRA, J. O. P. O papel de abelhas do gênero Centris na polinização e sucesso reprodutivo do muricizeiro (Byrsonima crassifolia, L.). 2001. 59f. Dissertação (Mestrado em Zootecnia) - Universidade Federal do Ceará (UFC), Fortaleza, 2001.

RENHE, I. R. T. et al. Obtenção de corante natural azul extraído de frutos de jenipapo. Pesquisa Agropecuária Brasileira, Brasília, v. 44, n. 6, p. 649-52, jun. 2009.

RUFINO, M. S. M. Qualidade e potencial de utilização de cajuís (Anacardium spp.) oriundos da vegetação litorânea do Piauí. 2004. 92f. Dissertação (Mestrado em Desenvolvimento e Meio Ambiente)- Universidade Federal do Piauí (UFPI), Teresina, PI, 2004.

SANTILLI, J. Socioambientalismo e novos direitos: proteção jurídica à diversidade biológica e cultural. São Paulo: Petrópolis, 2005.

SANTOS, B. S.; MENESES, M. P. G.; NUNES, J. A. Para ampliar o cânone da ciência: a diversidade epistemológica do mundo. In: SANTOS, Boaventura de Sousa (Org.). Semear outras soluções: os caminhos da biodiversidade e dos conhecimentos rivais. Porto, Portugal: Afrontamento, 2005. p. 19-101.

TARDÍO, J.Alimentossilvestres: la despensa más naturaly nutritiva. IMIDRA-Instituto Madrieñode Investigación y Desarrollo Rural Agrário e Alimentario. Ambienta, n. 95, p. 36-49, jun. 2011. Disponível em: http:// www.mapama.gob.es/ministerio/pags/Biblioteca/Revistas/pdf_AM\%2FAmbienta_2011_95_36_49.pdf.

\section{Sobre os autores:}

André Luís Aires Pinto: Mestre em Sociobiodiversidade e Tecnologias Sustentáveis pela Universidade da Integração Internacional da Lusofonia Afro-Brasileira (UNILAB). Graduado em Ciências Sociais pela Universidade Federal do Ceará. Atuou como consultor da AGENDHA para o Ministério do Desenvolvimento Agrário. Tem experiência na área de Sociologia e Antropologia, atuando principalmente nos seguintes temas: sociobiodiversidade, etnobotânica, índios tremembé, agricultura familiar e economia solidária. E-mail: andre.nutre@gmail.com

Francisca Joseli Freitas de Sousa: Graduanda em Agronomia pela Universidade da Integração Internacional da Lusofonia Afro-Brasileira (UNILAB). E-mail: joselisousa2010@gmail.com

Maria do Socorro Moura Rufino: Pós-doutora em Ciência e Tecnologia de Alimentos (PNPD/ Capes/UFC). Doutora em Fitotecnia (Bioquímica, Fisiologia e Tecnologia Pós-Colheita) pela UFERSA incluindo Estágio Doutorando no Exterior em Bioquímica da Nutrição no Departamento de Metabolismo e Nutrição (ICTAN/CSIC), da Espanha. Mestre em Desenvolvimento e Meio Ambiente (utilização sustentável dos recursos naturais) pela UFPI. Graduada em Agronomia 
pelo CCA/UFPI. Professora Efetiva da Universidade da Integração Internacional da Lusofonia Afro-Brasileira (UNILAB), lotada no Instituto de Desenvolvimento Rural/Curso de Agronomia na área de Bioquímica e Tecnologia do Processamento de Produtos Agropecuários. Professora do quadro permanente do Mestrado Acadêmico em Sociobiodiversidade e Tecnologias Sustentáveis (UNILAB). E-mail: marisrufino@pq.cnpq.br 
